\title{
Synthesis, docking, and preliminary in vitro/in vivo evaluation of MPP-dithiocarbamate-capped silver nanoparticle as dual-imaging agent for $5 \mathrm{HT}_{\text {IA }}$
}

This article was published in the following Dove Press journal: International Journal of Nanomedicine

\author{
Shubhra Chaturvedi' \\ Sangeeta Lal ${ }^{2}$ \\ Prasenjit Sen ${ }^{3}$ \\ Anil K Mishra' \\ 'Division of Cyclotron and \\ Radiopharmaceutical Sciences, \\ Institute of Nuclear Medicine \\ and Allied Sciences, New Delhi, \\ Delhi, ${ }^{2}$ Department of Physics, B.S. \\ College, Magadh University, Patna, \\ Bihar, ${ }^{3}$ School of Physical Sciences, \\ Jawaharlal Nehru University, New \\ Delhi, Delhi, India
}

\begin{abstract}
Methoxyphenyl piperazine is a versatile pharmacophore and has been exploited for targeting $5 \mathrm{HT}_{1 \mathrm{~A}}$ receptors. In the present study, silver nanoparticles were conjugated (capped) with methoxyphenyl piperazine-dithiocarbamate for application as targeted optical imaging agent at extremely low detection limits. Our results demonstrate an easy synthesis of the ligand methoxyphenyl piperazine-dithiocarbamate and silver nanoparticles and their conjugation was free from extraneous impurities.
\end{abstract}

Keywords: receptor imaging, optical imaging, targeted nanoparticles

\section{Introduction}

Neuroreceptor imaging is indispensable for understanding the pathophysiology of neuropsychiatric disorders and neurocognitive pathways. Selective and specific targeting of receptors in the central neural system enhances receptor imaging capability. Existing literature reports the specific and selective targeting of $5 \mathrm{HT}_{1 \mathrm{~A}}$ neuroreceptors using methoxyphenyl piperazine (MPP). ${ }^{1} \mathrm{MPP}$ is a versatile pharmacophore that can be modified for enhanced targeting and conjugation with other ligands for applications, such as imaging. In this study, MPP scaffold has been functionalized as dithiocarbamate (MPP-DTC) because DTC ligands are capable of complexation with a gamut of metal ions, which can be used as a signaling component for imaging. MPP-DTC and Ag nanoparticles (NPs) are conjugated for application as targeted optical imaging agent at extremely low detection limits. An added advantage of the DTC functionalization is the ligand ability to cross the blood-brain barrier because the lipophilicity requirements are not compromised. ${ }^{2}$

\section{Materials and methods}

The reagents were purchased from Sigma Chemical Co. Ltd. (St Louis, MO, USA). The HEK cell line used for the experiments was procured from National Centre for Cell Science (NCCS; Pune, India), which is under the Government of India. NCCS distributes cell lines only to registered organizations, which have qualified investigators to use cell lines in their research.

\section{Synthesis}

MPP was DTC functionalized in a single step using carbon disulfide. Briefly, to a stirred solution of MPP (1 eq, $0.2 \mathrm{mmol})$ in dichloromethane $(5 \mathrm{~mL})$, triethylamine ( $3 \mathrm{eq}, 0.6 \mathrm{mmol}$ ) was added. The solution was cooled in an ice-salt bath, and carbon 
disulfide ( $1 \mathrm{eq}, 0.2 \mathrm{mmol}$ ) was added dropwise to the solution with continuous stirring over a period of $30 \mathrm{~min}$. The reaction mixture was then brought to room temperature and stirred overnight. The pale yellow solution was evaporated, and the crude product was recrystallized from ethanol/diethyl ether. MPP-DTC was characterized using mass spectrometry and ultraviolet (UV) spectroscopy. Ag-NPs were synthesized by electro-explosion of wire (EEW technique). ${ }^{3}$ Briefly, a thin Ag wire is exploded in a thin Ag plate by passing a current density of $\sim 10^{10} \mathrm{~A} / \mathrm{m}^{2}$, in a time of $10^{-6} \mathrm{~s}$. The Ag-NPs were then conjugated to MPP-DTC in the presence of sodium acetate in water:methanol (1:1) solvent at room temperature.

\section{Particle characterization}

The physicochemical parameters of the NPs were evaluated using X-ray diffraction (XRD), transmission electron microscopy (TEM), fluorescence spectroscopy, ultraviolet-visible (UV-vis) spectra, and infrared (IR) spectroscopy before and after conjugation.

\section{Cytotoxicity}

In vitro cellular studies include MTT assay for cytotoxicity assessment on HEK cells. Exponentially growing cells were seeded (3,000 cells/well for HEK) in a 96-well microtiter plate. After $24 \mathrm{~h}$, media was replenished for all wells and cells were incubated with varying concentrations of the capped Ag-NPs at different time intervals (2, 6, 18, 24, and $48 \mathrm{~h}$ ). After the specified time, standard MTT assay was performed. Optical density was measured at $570 \mathrm{~nm}$ with a reference filter at $630 \mathrm{~nm}$. Percent surviving fraction was plotted as function of the treatment time for different doses of compound.

\section{Results and discussion}

MPP-DTC was synthesized in $>95 \%$ yield and was characterized using mass spectrometry, wherein the molecular mass peak at $m / z 267$ in negative mode (Figure 1) was obtained. The UV spectra of MPP-DTC showed $\lambda_{\max }$ at 255 and $285 \mathrm{~nm}$ corresponding to $\pi-\pi^{*}$ and $\mathrm{n}-\pi^{*}$ transition. The contaminating $\mathrm{Na}_{2} \mathrm{CS}_{3}$ was not found at $330 \mathrm{~nm} .{ }^{4} \mathrm{Ag}-\mathrm{NPs}$ were formed through EEW technique. This technique is a novel, physical, top-down approach, wherein the flow of the current through the Ag wire plate leads to heating at the point of contact, followed by melting. The melted Ag metal at the point of contact is further heated increasing the current density that leads to the evaporation of $\mathrm{Ag}$ metal and subsequent plasma formation. This plasma is contained by the self-induced magnetic field. When the vapor pressure

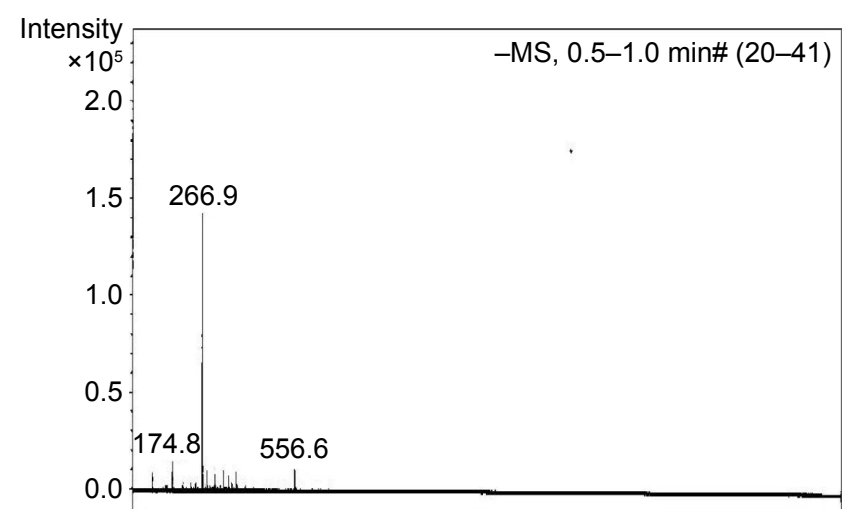

Figure I Mass spectra of methoxyphenyl piperazine-dithiocarbamate. Abbreviation: -MS, negative ion mode mass spectrometry.

of the plasma overwhelms the self-induced magnetic field, explosion occurs and the plasma products are dispersed in the medium with high speed. Synthesized Ag-NPs are free from extraneous impurities as no chemicals have been used. Ag-NPs and MPP-DTC conjugation was carried out in a single-step reaction. MPP-DTC when docked on the $5 \mathrm{HT}_{1 \mathrm{~A}}$ receptor homology model retained its binding with a glide score of -4.94 .

The physicochemical parameters are depicted in Figure 2. XRD pattern (Figure 2A) of the Ag-NPs corresponds to that of face centered cubic. On conjugation with MPP-DTC, only a slight distortion was observed. The capped MPP-DTC-Ag-NPs reflect peaks corresponding to (111), (200), (220), (311), and (222). Peaks in the region $(0<2 \theta \leq 35)$ match with the standard XRD data of $\mathrm{Ag}_{2} \mathrm{CO}_{3}$, the formation of which is attributed to carbon-dioxide in atmosphere. ${ }^{5}$ The UV-vis spectra (Figure 3A) showed a peak at $\sim 400 \mathrm{~nm}$ characteristic of Ag-NPs and assigned to surface plasmon resonance (SPR). This peak, due to the SPR, is dependent on medium's refractive index, size and shape of NPs, and absorption substance at the surface of the NPs. UV-vis spectra of MPP-DTC-Ag-NPs (Figure 3B) show two resonant peak absorption at $\sim 250$ and $300 \mathrm{~nm}$ (characteristic peaks of DTC), indicating conjugation although the peak at $400 \mathrm{~nm}$ got compromised because of capping. The broadening of the peak in $410-430 \mathrm{~nm}$ is due to the presence of DTC that acts as electron donor and changes the bonding pattern of the Ag-NPs. ${ }^{6-8}$ The fluorescence spectra of the Ag-NPs dispersed in water exhibit a single fluorescence emission at $300 \mathrm{~nm}$ when it is excited in the range of either 215-235 or 255-280 nm $\left(\lambda_{\text {ex }}\right)$, whereas the MPP-DTC-Ag-NPs fluorescence with a singular emission at $425 \mathrm{~nm}$ for $\lambda_{\text {ex }}$ is excited in the range of 230-250 nm (Figure 4A). The fluorescence emission peak intensity is maximum at $425 \mathrm{~nm}$ at $\lambda_{\text {ex }} 235 \mathrm{~nm}$ and 
A

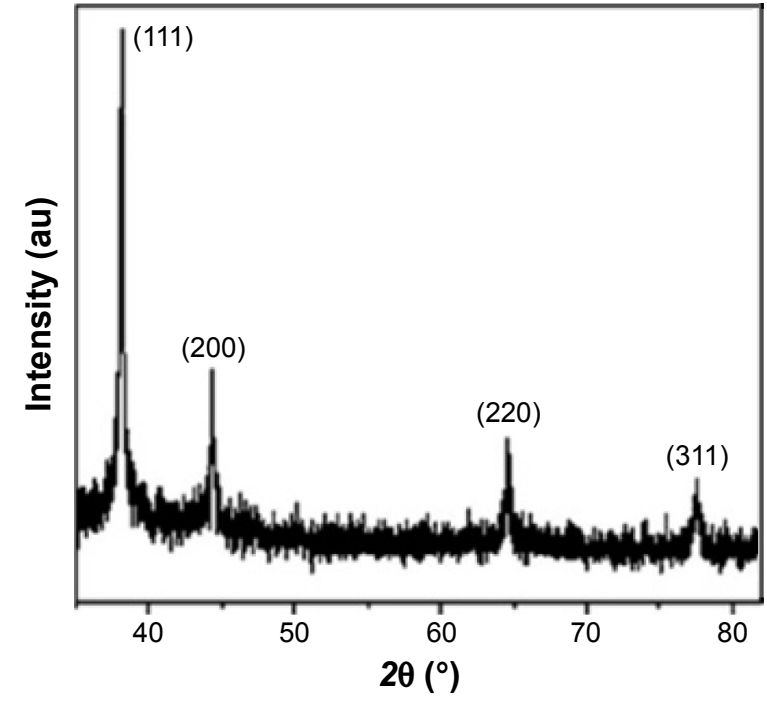

B

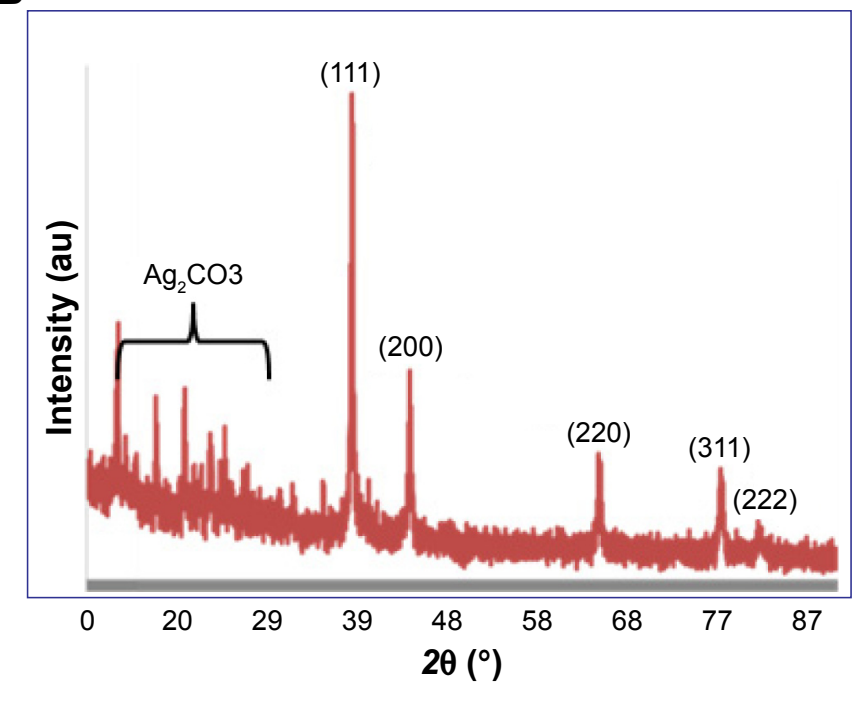

Figure 2 X-ray diffraction patterns of (A) Ag-NPs and (B) MPP-DTC-Ag-NPs.

Abbreviations: au, arbitrary unit; MPP-DTC, methoxyphenyl piperazine-dithiocarbamate; NPs, nanoparticles.

decreases thereafter as $\lambda_{\text {ex }}$ increases. This indicates that resonant absorption/maximum transition probability is at $\lambda_{\text {ex }} 235 \mathrm{~nm}$ for capped Ag-NPs. The reason for the red shift could be attributed to the change in the environment of the MPP-DTC-Ag-NPs.

The IR spectra (Figure 4B) indicated the formation of silver-sulfide bonds by the disappearance of 2,550-2,600 $\mathrm{cm}^{-1}$ peak. The typical DTCs frequencies ${ }^{9}$ were 1) peak at $1,460 \mathrm{~cm}^{-1}$ associated primarily with the "thioureide", 2) peak at $1,503 \mathrm{~cm}^{-1}$ indicating the polar structure of DTC, and 3) peak at $1,016 \mathrm{~cm}^{-1}$ indicating the symmetrical binding mode of DTC. The size of the synthesized Ag-NPs in TEM images was $10-20 \mathrm{~nm}$. Conjugation with MPP-DTC resulted in NPs with similar size, but exact size could not be determined due to clustering. The cellular toxicity studies performed on HEK cell lines showed that the MPP-DTC-Ag-NPs were nontoxic up to a dose of $1 \mathrm{mM}$.

\section{Conclusion}

Our findings establish 1) easy synthesis of the ligand MPPDTC, 2) easy synthesis of Ag-NPs free from extraneous impurities, 3) conjugation of Ag-NPs with MPP-DTC, and 4) evaluation of physicochemical parameters. Further work should concentrate on exact size and polydispersity index determination of the MPP-DTC-Ag-NPs and their application for optical imaging.
A

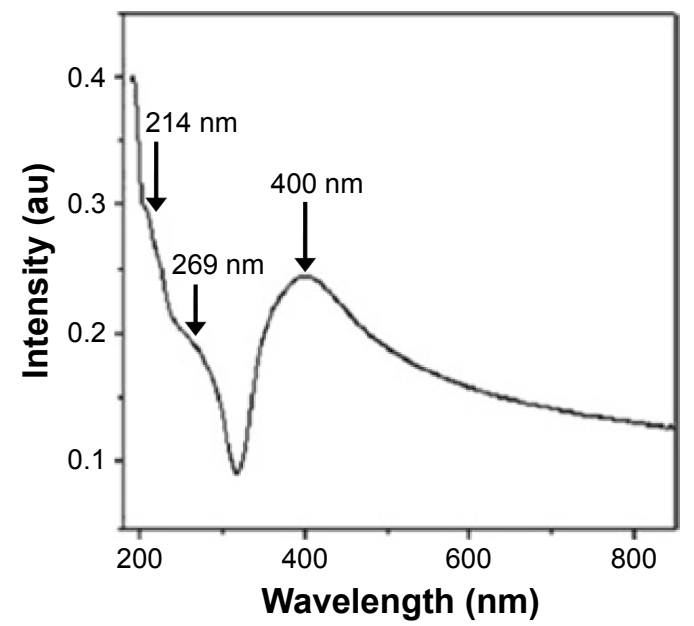

B

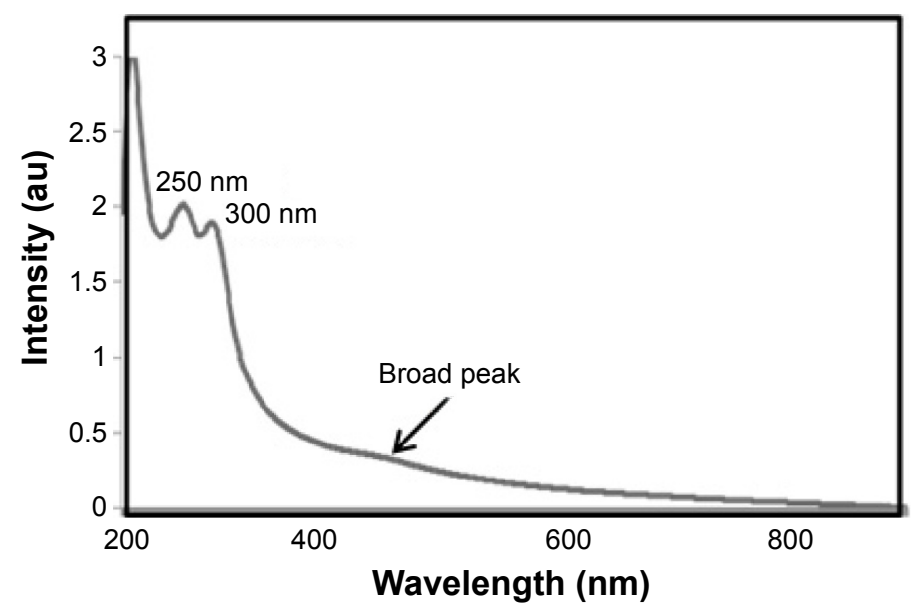

Figure 3 UV-vis spectra of (A) Ag-NPs and (B) MPP-DTC-Ag-NPs.

Abbreviations: au, arbitrary unit; MPP-DTC, methoxyphenyl piperazine-dithiocarbamate; NPs, nanoparticles; UV-vis, ultraviolet-visible. 


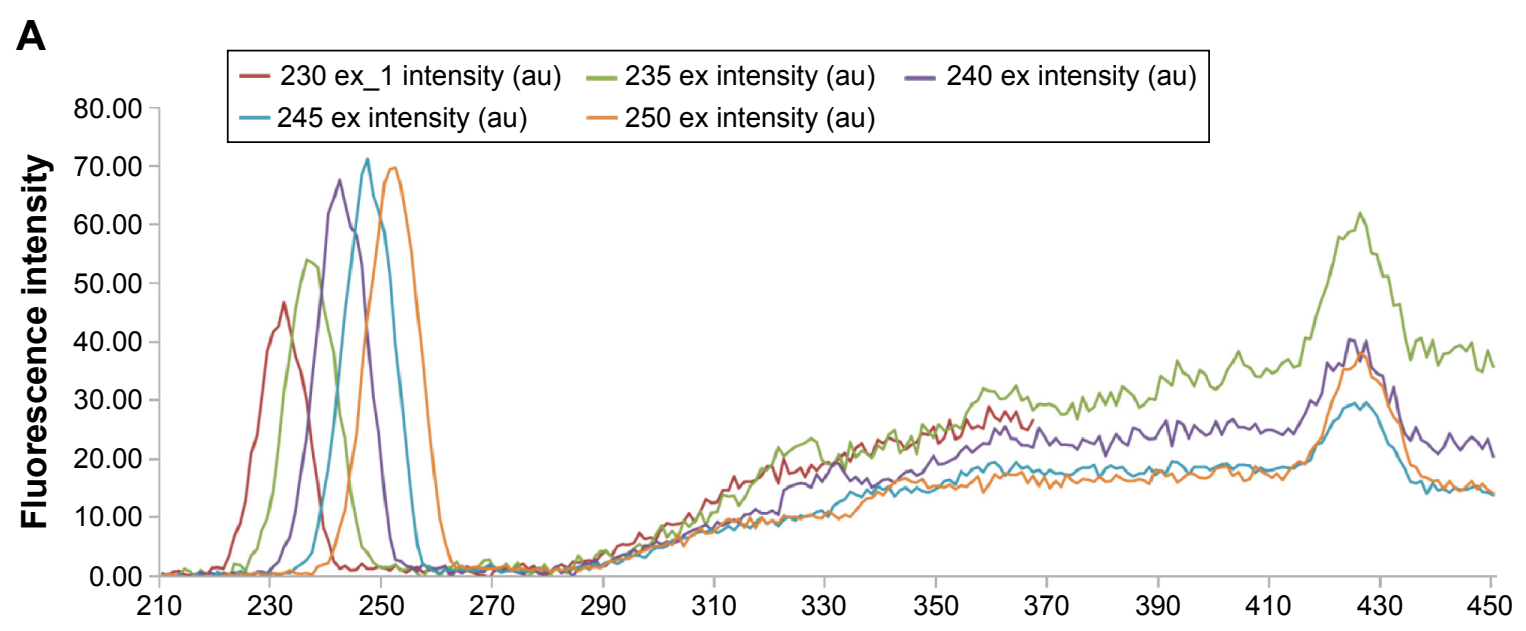

B

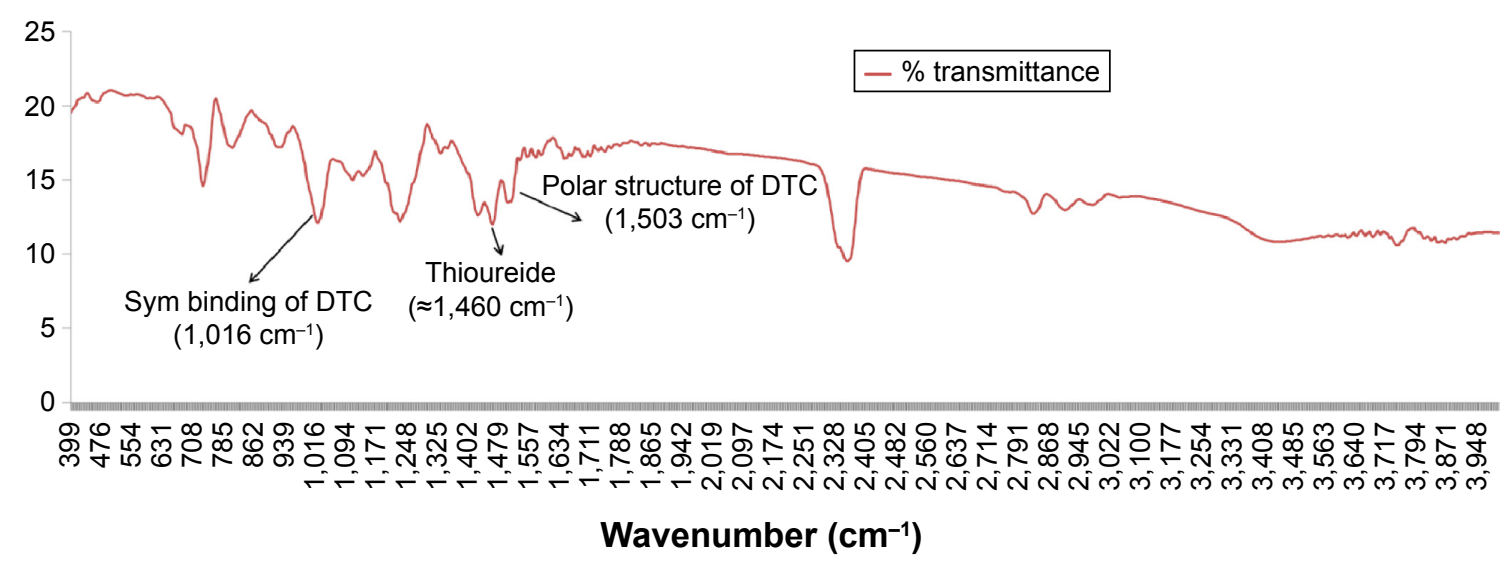

Figure 4 Characterization of MPP-DTC-Ag-NPs. (A) Fluorescence spectra of MPP-DTC-Ag-NPs (B) FT-IR spectra of MPP-DTC-Ag-NPs.

Abbreviations: au, arbitrary unit; DTC, dithiocarbamate; FT-IR, Fourier transform-infrared; MPP-DTC, methoxyphenyl piperazine-dithiocarbamate; NPs, nanoparticles; sym, symmetrical.

\section{Acknowledgment}

We thank Dr RP Tripathi, Director, Institute of Nuclear Medicine and Allied Sciences, and School of Physical Sciences, Jawaharlal Nehru University, for providing the necessary facilities.

\section{Disclosure}

The authors report no conflicts of interest in this work.

\section{References}

1. Yang W, Lin Y, Zhang X, Zhang J, Wang X. Synthesis of several MPP derivatives for $99 \mathrm{mTc}$-labelling and evaluated as potential 5-HT1A receptor imaging agents. Sci China Chem. 2011;54(7):1148-1154.

2. Chaturvedi S, Kaul A, Yadav N, Singh B, Mishra AK. Synthesis, docking and preliminary in vivo evaluation of serotonin dithiocarbamate as novel SPECT neuroimaging agent. MedChemComm. 2013;4(6):1006-1014.

3. Sen P, Ghosh J, Abdullah A, Kumar P. Preparation of $\mathrm{Cu}, \mathrm{Ag}, \mathrm{Fe}$ and Al nanoparticles by the exploding wire technique. J Chem Sci. 2003; 115(5-6):499-508.
4. Shankaranarayana ML, Patel CC. The electronic spectra of some derivatives of xanthic, dithiocarbamic and trithiocarbonic acids. Acta Chem Stand. 1965;19:1113-1119.

5. Liu C, Yang X, Yuan H, Zhou Z, Xiao D. Preparation of silver nanoparticle and its application to the determination of ct-DNA. Sensors. 2007;7(5):708-718.

6. Yeshchenko OA, Dmitruk IM, Alexeenko AA, Kotko AV, Verdal J, Pinchuk AO. Size and temperature dependence of the surface plasmon resonance in silver nanoparticles. Ukr J Phys. 2012;57:266.

7. Mankad V, Kumar RK, Jha PK. Investigation of blue-shifted plasmon resonance: an optical properties study of silver nanoparticles. Nanosci Nanotechnol Lett. 2013;5(8):889-894.

8. Mogensen KB, Kneipp K. Size-dependent shifts of plasmon resonance in silver nanoparticle films using controlled dissolution: monitoring the onset of surface screening effects. $J$ Phys Chem C. 2014;118(48): 28075-28083.

9. Mathew EJ, Studies on Some Metal Complexes of Dithio Ligands [doctoral thesis]. Cochin, India: Cochin University of Science and Technology; 1990. 
International Journal of Nanomedicine

\section{Publish your work in this journal}

The International Journal of Nanomedicine is an international, peerreviewed journal focusing on the application of nanotechnology in diagnostics, therapeutics, and drug delivery systems throughout the biomedical field. This journal is indexed on PubMed Central, MedLine, CAS, SciSearch ${ }^{\circledR}$, Current Contents ${ }^{\circledR} /$ Clinical Medicine,

Journal Citation Reports/Science Edition, EMBase, Scopus and the Elsevier Bibliographic databases. The manuscript management system is completely online and includes a very quick and fair peer-review system, which is all easy to use. Visit http://www.dovepress.com/ testimonials.php to read real quotes from published authors.

Submit your manuscript here: http://www.dovepress.com/international-journal-of-nanomedicine-journal 